\title{
Risk factors in the development of cervical intraepithelial neoplasia in women with vulval warts
}

\author{
S A WALKINSHAW,* J DODGSON,* D J McCANCE, $\dagger$ I D DUNCAN* \\ From the *Department of Obstetrics and Gynaecology, Ninewells Hospital, Dundee, and the $\dagger$ Department of \\ Microbiology, United Medical and Dental School, Guy's Campus, Guy's Hospital, London
}

SUMMARY Of 59 women referred with vulval warts whose cervices were assessed colposcopically for the presence of cervical intraepithelial neoplasia (CIN) before local treatment of the wart lesions, 17 had histologically proved CIN, 12 had histologically proved cervical wart virus infection, and 30 had abnormality on colposcopy or cytology. Seven of the 17 with CIN had no abnormality on cervical cytology.

No differences in sexual behaviour, smoking habit, or oral contraceptive use were seen between women with CIN and those with no cervical abnormality. Viral DNA typing of the vulval lesions was carried out, but there were no differences in the distribution of viral types between the three different histological groups.

Of the 30 women with no abnormality at the initial visit, 23 were followed up colposcopically and cytologically for one to two years. Three of them developed CIN after adequate treatment of the vulval lesions despite the absence of cervical abnormalities on colposcopy at the time of treatment.

Studying the known factors linked with CIN failed to show why some women with vulval warts develop CIN, even after treatment of the warts, and others do not. The large number of false negative results on cervical cytology in our patients suggests that women presenting with vulval warts should be screened colposcopically in the first instance. Close follow up of women whose warts are treated and who are thought to have no cervical abnormality at that assessment is essential.

Despite the circumstantial evidence implicating genital warts and infection with human papillomavirus (HPV) in the aetiology of cervical cancer, ${ }^{12}$ not all women with genital warts develop cervical cancer. Prospective studies of women with cervical HPV infection have indicated that $12 \cdot 1 \%$ to $13.4 \%$ of these lesions will progress to cervical intraepithelial neoplasia (CIN) over a variable time, ${ }^{34}$ but there is little information on the risk of developing CIN in women presenting with overt vulval wart infection whose cervices are not affected, and no data are available about the possible effects of treatment of the vulval lesions on the subsequent risk of CIN.

Walker et al showed that almost one third of women presenting with vulval warts would have histological evidence of CIN at initial assessment or within six

Address for reprints: Dr S A Walkinshaw, Department of Obstetrics and Gynaecology, Princess Mary Maternity Hospital, Newcastle upon Tyne NE2 3BD

Accepted for publication 28 April 1988 months of presentation..$^{5}$ Although follow up was short, three of the 22 women colposcopically healthy at their first visit developed colposcopic abnormalities within six months. Francheschi et al indicated that in women with genital warts who had normal cervical cytology and for whom further cervical smears were available, $10 \%$ developed an abnormal smear at a mean of three to four years. ${ }^{6}$

The progression of genital warts to cervical premalignant disease must therefore largely depend on other factors. Such external factors interact in other animal papillomaviruses, such as those of rabbits and cattle, to induce tumours. ${ }^{78}$ Proposed cofactors in cervical cancer include cigarette smoking, prolonged oral contraceptive use, and type of HPV..$^{-13}$

In view of the large numbers of women with genital warts presenting to gynaecologists, dermatologists, genitourinary medicine specialists, and general practitioners, it would be useful to assess differences in the prevalence of these other risk factors in women with and without CIN at the time of initial presentation. 
This might permit the identification of high risk subgroups for whom intensive cytological or colposcopic surveillance would be worthwhile. Longer term follow up of women without cervical infection after being treated for vulval warts might give valuable information about the real day to day risks for women who develop CIN.

We therefore assessed, treated, and followed up for two years a group of women presenting with vulval warts.

\section{Patients and methods}

\section{STUDY GROUP}

The gynaecology, dermatology and genitourinary medicine clinics of Ninewells Hospital referred 59 women with vulval warts for colposcopic assessment. All the women gave full informed consent. For each woman we noted age, parity, marital status, number of cigarettes smoked and duration of smoking habit, contraceptive used and duration of use, age at first coitus, number of sexual partners, and history of genital warts in partners.

All women underwent colposcopic examination by one of us (JD). A cervical smear was taken using a modified Ayre's spatula. Directed biopsy specimens were taken of colposcopically abnormal epithelium, and a representative biopsy specimen of the cervical transformation zone was obtained from each woman without detectable abnormality. We used standard criteria for the histological diagnosis of CIN or HPV..$^{1415}$

Overt warts were sampled, and the tissue was snap frozen in liquid nitrogen. As the women had been referred initially for treatment of vulval warts, all were offered treatment with podophyllin, 5-fluoracil cream, or diathermy under general anaesthesia when appropriate. Women with histological evidence of
CIN were treated with the Semm cold coagulator. ${ }^{16}$ All women with CIN were followed up at the cervix clinic at Ninewells Hospital. Women with benign histology results were reassured and asked to reattend one and two years after the initial examination when the colposcopic, cytological, and, when appropriate, histological assessments were repeated by the same assessor (JD).

\section{VIRAL DNA ANALYSIS}

DNA was extracted in high volume $0.5 \%$ sodium dodecyl sulphate, $0.1 \mathrm{~mol} / 1$ sodium chloride, and 0.05 trometamol (TRIS) hydrochloride ( $\mathrm{pH} \mathrm{8)}$ containing $200 \mathrm{mg} / 1$ proteinase $\mathrm{K}$ (Boehringer); digested for 1224 hours at $37^{\circ} \mathrm{C}$; and then extracted using phenol and chloroform and stored in TE (TRIS $10 \mathrm{mmol} / \mathrm{l}$ and EDTA (ethylenediaminetetra-acetic acid) $1 \mathrm{mmol} / \mathrm{l}$ ) buffer at $-20^{\circ} \mathrm{C}$.

Samples were digested with the bacterial restriction enzyme $P$ st $I$, the fragments were separated on agarose gels, and DNA was transferred to nitrocellulose filters as described previously. ${ }^{17}$ The filters were hybridised at low stringency (melting temperature $-40^{\circ} \mathrm{C}$ ) with linear HPV DNA probes labelled with radiophosphorus, exposed to Fuji $x$ ray film, and then washed at high stringency (melting temperature $-12^{\circ} \mathrm{C}$ ) before re-exposure. All samples were probed for the presence of HPV types 6, 11, and 16.

\section{Results}

Of the 59 women referred, 17 had histological evidence of CIN (seven had CIN I, seven had CIN II, and three had CIN III), 12 had evidence of cervical HPV infection in the absence of CIN, and 30 had no cytological, colposcopic, or histological abnormality at the first visit.

Five of the 12 women with cervical HPV had normal

Table 1 Demographic data of 59 women with vulval warts

\begin{tabular}{|c|c|c|c|}
\hline \multirow[b]{2}{*}{ Patient characteristics } & \multicolumn{3}{|c|}{ Cervical histology results showing: } \\
\hline & $\begin{array}{l}C I N \\
(n=17)\end{array}$ & $\begin{array}{l}H P V \\
(n=12)\end{array}$ & $\begin{array}{l}\text { No abnormality } \\
(n=30)\end{array}$ \\
\hline 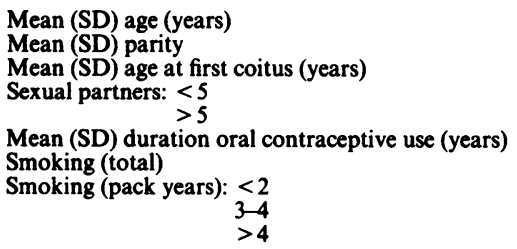 & $\begin{array}{l}22 \cdot 7(4 \cdot 45) \\
1 \cdot 32(2 \cdot 18) \\
17 \cdot 1(1 \cdot 2) \\
16 \\
1 \\
1 \cdot 56(1 \cdot 46) \\
8 \\
1 \\
4 \\
3\end{array}$ & $\begin{array}{l}22 \cdot 4(3 \cdot 55) \\
1 \cdot 33(1 \cdot 82) \\
16 \cdot 7(1 \cdot 5) \\
10 \\
2 \\
4 \cdot 4(2 \cdot 54)^{*} \\
9 \\
1 \\
5 \\
3\end{array}$ & $\begin{array}{l}25 \cdot 7(5 \cdot 9)^{\star} \\
1 \cdot 07(1 \cdot 33) \\
18 \cdot 0(1 \cdot 3) \\
28 \\
2 \\
2 \cdot 2(2 \cdot 01) \\
12 \\
2 \\
2 \\
8\end{array}$ \\
\hline
\end{tabular}

CIN = cervical intraepithelial neoplasia

HPV = human papillomavirus.

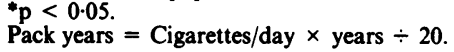


Table 2 Human papillomavirus (HPV) DNA types obtained from 56 women with vulval warts

\begin{tabular}{llll}
\hline & \multicolumn{3}{l}{ Cervical histology results showing: } \\
\cline { 2 - 4 } HPV DNA type & $\begin{array}{l}C I N \\
(n=16)\end{array}$ & $\begin{array}{l}H P V \\
(n=11)\end{array}$ & $\begin{array}{l}\text { No } \\
\text { abnormality } \\
(n=29)\end{array}$ \\
\hline No detectable DNA & 8 & 6 & 16 \\
6a & 0 & 1 & 1 \\
6b & 1 & 0 & 0 \\
6(Dundee) & 6 & 4 & 12 \\
11 & 1 & 0 & 0 \\
16 & 0 & 0 & 0 \\
\hline
\end{tabular}

$\mathrm{CIN}=$ cervical intraepithelial neoplasia.

cervical cytology at the time of diagnosis. Seven of the 17 women with CIN, including two of the three with CIN III, also had normal cytology.

Table 1 shows the demographic data of the three groups. No differences in sexual behaviour were found between the groups. Women with vulval warts but normal cervices were older than those in both groups with histological abnormalities $(t=1.93, p<0.1$ compared with women with $\mathrm{CIN} ; \mathrm{t}=2.174, \mathrm{p}<0.05$ compared with women with HPV). Most of the 59 women took oral contraceptive steroids. No differences in duration of their use were noted between women with CIN and those with normal cervices, but those with cervical HPV only had used contraceptive steroids for significantly $(p<0.05)$ longer than women in both the other groups. There were no differences in the proportion of smokers in the CIN and normal groups, although the women in the normal group tended to be heavier smokers. A higher proportion of women with cervical HPV smoked, but they were not heavier smokers than any women in the other two groups.

HPV DNA was extracted from vulval warts taken from 56 patients. Viral DNA was identified in 26 , and table 2 shows the distribution of types. The virus named HPV (Dundee) has not yet been typed; the DNA hybridised to the HPV 6 probes under stringent conditions, but its restriction profile with the restriction enzyme Pst $I$ differed from the known profiles of HPV types $6 \mathrm{a}, 6 \mathrm{~b}$, or $6 \mathrm{c}$. It may represent a variant or a possible DNA degradation problem in the extraction. HPV 16 was not identified in any wart tissue. HPV DNA was identified as often in the warts of women with healthy cervices as in those with CIN or cervical HPV.

\section{FOLLOW UP STUDIES}

All women treated for CIN were followed up yearly at the cervix clinic at Ninewells Hospital. Treatment failed in one, who was treated again at one year.

Nine of the 12 women with cervical HPV attended for one year follow up. Cervical HPV persisted histologically in one, one had an atypical (class 2) smear with normal colposcopic findings, and the remaining seven had no colposcopic or cytological abnormality. Of the 30 women with normal findings at the initial visit, 18 attended for one year review; one had developed cervical HPV and one had developed CIN I, which was treated with the cold coagulator.

Five of the nine women with cervical HPV followed up at one year attended again for two year review. Two of them had developed CIN I, the HPV lesion persisting at year 1 had resolved, but the cytological abnormality in the other woman persisted, although her colposcopy result was again normal. Fourteen women initially normal were seen at two years (nine previously seen at year 1 plus five who did not attend at year 1). One had developed CIN I and one (normal at year 1) had developed CIN III. The cervical HPV lesion seen at year 1 had resolved, and one woman had an atypical (class 2) smear but normal colposcopy.

Table 3 shows details of the five women who developed CIN.

\section{Discussion}

Our finding of 17 women with established CIN at initial screening confirms the conclusions of Walker $e t$ al that women with genital warts are at high risk of having CIN. ${ }^{5}$ These findings reinforce the view that women attending for the first time with genital warts required screening for cervical intraepithelial neoplasia. The type of screening is still controversial, but our rather alarming finding of many false negative

Table 3 Characteristics of five women who developed cervical intraepithelial neoplasia (CIN) one or two years after being treated for vulval warts

\begin{tabular}{lllll}
\hline Age & Original histology & HPV type & Smoking (pack years) & Oral contraceptive use (years) \\
\hline 25 & Normal & 6 N & 0 & 5 \\
21 & Normal & Not tested & 0 & 3 \\
21 & Normal & 6(Dundee) & 0 & 4 \\
21 & HPV & Not tested & $3 \cdot 8$ & 6 \\
23 & HPV & 6(Dundee) & 6 & 8 \\
\hline
\end{tabular}

HPV = human papillomavirus

Pack years $=$ cigarettes/day $\times$ years $\div 20$. 
results of cervical cytology (all in smears taken at the time of colposcopy) in a group of women with colposcopic and histological abnormality suggests that screening should be by colposcopy. The implications of such a policy would be profound, given the numbers of women to be screened. Screening of this nature would almost certainly need to take place in genitourinary medicine clinics and would require considerable financial and training resources.

We were unable to show any differences between women with CIN and those with normal cervices at initial screening in respect of sexual behaviour, smoking habit, oral contraceptive use, or HPV type. This suggests that the factors that increase the risk of CIN in women with vulval warts have not yet been identified, although the small numbers in our study make any firm conclusions debatable. Walkinshaw et $a l$ who studied a larger group of women with CIN and cervical HPV, suggested that women with CIN who smoked were heavier smokers than those with HPV infection who smoked. ${ }^{18}$ Our study did not confirm this finding. The larger study did not include data on duration of smoking. Other studies implicating oral contraceptives or smoking in cervical cancer used "normal" women as controls and did not give data on past or current genital warts. ${ }^{9-12}$

Lesions containing HPV 16 are more likely to progress to high grade CIN. ${ }^{13}$ We were unable to identify this viral type in any specimen. Durst et al have shown that HPV 16 is rarely identified in vulval warts, ${ }^{19}$ although Schneider et al identified HPV 16 more readily in condylomata and wart virus infected tissue in the absence of dysplasia. ${ }^{20} \mathrm{HPV}$ types 6 and 11 are commonly identified in vulval warts, and it is women with vulvar warts with HPV 6 and 11 who are said to be at risk of CIN. HPV of these types is found in CIN lesions, including those classified as CIN III. ${ }^{7021}$ No biopsy specimens from the cervix were HPV typed, so differences in cervical HPV isolation may have existed between our study groups as other studies have shown that HPV 16 is more common in CIN. ${ }^{22}$ There is, however, a high correlation between the type of virus identified in lower genital warts and the viral type found in cervical lesions in the same woman. ${ }^{20}$ Women in whom viral DNA was identified may therefore have had the same viral type in the cervical lesion. No differences in the incidence of the different viral types was seen between normal cervices and those with histological abnormality.

Women with cervical HPV at initial screening were significantly younger than the normal group, had used oral contraceptive steroids for longer than both the normal and CIN groups, and were more likely to smoke than both the other groups. It is not clear why this group should have been different. One reason may be that prolonged exposure to oral contraceptives in young women who smoke makes the cervix more susceptible to HPV infection. Why these differences should not be maintained in women with established CIN, however, is not clear.

The longer term follow up data gives cause for concern in women with genital warts. In all, 23 women initially normal colposcopically and cytologically were followed up at one or two years. All were treated for their vulval warts and were advised to encourage their sexual partners to seek examination and treatment. Three of them developed CIN, including one who developed CIN III. Even assuming that the women who did not attend for review remained free of CIN, this would represent a $10 \%$ progression rate to $\mathrm{CIN}$ in two years despite clinically adequate treatment of obvious lesions and no colposcopic evidence of cervical infection. The numbers studied were too small to show any differences in smoking, contraceptive use, or HPV type. The finding of two patients with cervical HPV infection developing CIN is consistent with previous studies. ${ }^{34}$

Women with overt genital warts represent a high risk group likely to have existing CIN when first presenting for treatment. CIN can develop despite adequate primary treatment of existing vulval lesions before any detectable cervical pathology. In this small study we have been unable to show any association between smoking, oral contraceptive use, or HPV type and the presence or development of CIN in women with vulval warts. We therefore suggest that women presenting for treatment of genital warts should be assessed colposcopically as well as cytologically. All histological abnormalities should be treated in view of the well established evidence on the progression of cervical HPV to CIN. In the absence of cytological and colposcopic abnormality at initial assessment, these women, even after treatment, should have yearly cervical cytology tests as a minimum follow up, and colposcopy at intervals may have to be considered. Large follow up studies of women treated for genital warts will be required to establish any possible links between progression and other potential aetiological factors.

We thank colleagues in the departments of gynaecology, dermatology, and genitourinary medicine of Ninewells Hospital for allowing us to study their patients. We also thank nursing and clerical staff at the cervix clinic, Ninewells Hospital, Bhajan Chahal for technical assistance with the DNA typing, and Mrs I White for secretarial assistance. The DNA typing was made possible through a grant from Tayside Health Board (R 193) to Dr S Walkinshaw.

\section{References}

1 Singer A, Walker P, McCance DJ. Genital wart virus infections: nuisance or potentially lethal? $\mathrm{Br}$ Med J 1984;288:735-7.

2 Anonymous. Genital warts, human papillomavirus, and cervical 
cancer. Lancet 1985;ii:1045-6.

3 Mitchell H, Drake M, Medley G. Prospective evaluation of risk of cervical cancer after cytological evidence of human papillomavirus infection. Lancet 1986;i:573-5.

4 Syrjanen K, Vayrynen M, Saarikoski S, et al. Natural history of cervical human papillomavirus (HPV) infections based on prospective follow-up. Br J Obstet Gynaecol 1985;92:1086-92.

5 Walker PG, Singer A, Dyson JL, Oriel JD. Natural history of cervical epethelial abnormalities in patients with vulval warts. British Journal of Venereal Diseases 1983;59:327-9.

6 Franceschi S, Doll R, Gallway J, La Vecchia C, Peto R, Spriggs AI. Genital warts and cervical neoplasia: an epidemiological study. Br J Cancer 1983;48:621-8.

7 zur Hausen $\mathrm{H}$. The role of viruses in human tumours. Adv Cancer Res 1980;33:77-107.

8 Jarret WFH, McNeil PE, Grimshaw WTR, Selman IE, McIntyre WIM. High incidence of cattle cancer with possible interaction between an environmental carcinogen and a papillomavirus. Nature 1978;274:215-7.

9 Harris RWC, Brinton LA, Cowdell RH, et al. Characteristics of women with dysplasia or carcinoma in situ of the uterine cervix. Br J Cancer 1980;42:359-69.

10 WHO collaborative study of neoplasia and steroid contraceptives. Invasive cervical cancer and combined oral contraceptives. $\mathrm{Br}$ Med J 1985;290:961-5.

11 Lyon JL, Gardiner JW, West DW, Stanish WT, Hebartson RM. Smoking and carcinoma in situ of the uterine cervix. Am J Public Health1983;73:558-62.

12 Trevathan E, Layde P, Webster LA, Adams, JB, Benigno BB, Ory W. Cigarette smoking and dysplasia and carcinoma in situ of the uterine cervix. JAMA 1983;250:499-502.

13 Campion MJ, McCance DJ, Cuzick J, Singer A. Progressive potential of mild cervical atypia: prospective cytological, col- poscopic and virological study. Lancet 1986;ii:231-41.

14 Dyson JL, Walker PG, Singer A. Human papillomavirus infection of the uterine cervix: histological appearances of 28 cases identified by immunohistochemical techniques. J Clin Pathol 1984;37:126-30.

15 Buckley CH, Butler EB, Fox H. Cervical intraepithelial neoplasia. J Clin Pathol 1982;35:1-13.

16 Duncan ID. The Semm cold coagulator in the management of cervical intraepithelial neoplasia. Clin Obstet Gynecol 1983;26:996-1006.

17 McCance DJ, Walker PG, Dyson JL, Coleman DV, Singer A. Presence of human papillomavirus DNA sequences in cervical intraepithelial neoplasia. Br Med J 1983;287:784-8.

18 Walkinshaw SA, Roberts ADG, Cordiner JW. Evidence for possible interaction between human papillomavirus and environmental cofactors in women with cervical intraepithelial neoplasia. Gynaecological Laser Surgery 1987;3:73-9.

19 Durst M, Gissmann L, Ikenberg H, zur Hausen H. A papillomavirus DNA from a cervical carcinoma and its prevalence in cancer biopsies from different geographical regions. Proc Natl Acad Sci USA 1983;80:3812-5.

20 Schneider A, Sawada E, Gissmann L, Shah K. Human papillomavirus in women with a history of abnormal papanicolou smears and their male partners. Obstet Gynecol. 1987;69:554-62.

21 Gissmann L, Wolnik L, Ikenberg I, Koldovsky U, Schnurch HG, zur Hausen H. Human papillomavirus types 6 and 11 DNA sequences in genital and laryngeal papillomas and in some cervical cancers. Proc Natl Acad Sci USA 1983;80:560-3.

22 McCance DJ, Campion MJ, Clarkson PC, Chesters PM, Jenkins D, Singer A. Prevalence of human papillomavirus type 16 DNA sequences in cervical intra-epithelial neoplasia and invasive carcinoma of the cervix. Br JObstet Gynaecol 1985;92:1101-5. 